\title{
Adsorption of Congo Red Dye from Aqueous Solution Using Agricultural Waste
}

\author{
Enenebeaku K. Conrad ${ }^{1}$, Okorocha J. Nnaemeka ${ }^{1}$, Enenebeaku E. \\ Uchechi $^{2}$, Anukam Basil ${ }^{1}$, Onyeocha O. Veronica ${ }^{1}$, Ogukwe E. Cynthia ${ }^{1}$, \\ Oguzie E. Emeka ${ }^{1}$

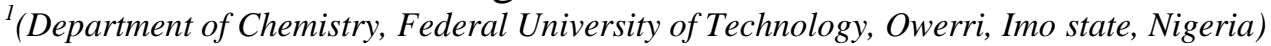 \\ ${ }^{2}$ (Department of Biotechnology, Federal University of Technology, Owerri, Imo State, Nigeria)
}

\begin{abstract}
The potential of Breadfruit seed shell powder, for the removal of congo red (CR) dye from aqueous solution was investigated. The adsorbent was characterized by FTIR and SEM analysis. Batch adsorption studies were conducted and various parameters such as contact time, adsorbent dosage, initial dye concentration, $p H$ and temperature were studied to observe their effects in the dye adsorption process. The optimum conditions for the adsorption of CR onto the adsorbent (BFSSP) was found to be: contact time (60mins), $\mathrm{pH}$ (2.0) and temperature (303K) for an initial CR dye concentration of $500 \mathrm{mg} / \mathrm{L}$ and adsorbent dose 1.0g. The experimental equilibrium adsorption data fitted best and well to the Freundlich isotherm model. The maximum adsorption capacity was found to be $16.00 \mathrm{mg} / \mathrm{g}$. The kinetic data conformed to the pseudo-secondorder kinetic model, suggesting that the rate limiting step may be chemisorptions. Thermodynamic quantities such as Gibbs free energy $\left(\Delta G^{0}\right)$, enthalpy $\left(\Delta H^{0}\right)$ and entropy $\left(\Delta S^{0}\right)$ were evaluated. The negative values of $\Delta G^{0}$ and the negative value of $\Delta H^{0}$ obtained indicated the spontaneous and exothermic nature of the adsorption process while the negative $\Delta S^{0}$ value obtained indicated decreased randomness during the adsorption process.

Keywords: Adsorption, Breadfruit seed shell powder, Congo red, Isotherms, Kinetics, Thermodynamics.
\end{abstract}

\section{Introduction}

The pollution of water resources due to the disposal of dye based effluents has been an increasing worldwide concern for the last few decades. Dyes are natural or synthetic coloured organic compounds having the property of imparting their colours to other substances. Although there are many natural dyes available, the ingrain coloured by these are neither bright nor durable. Hence synthetic dyes are generally used which are cheap and readily available [1].They also produce brighter colours and are resistant to light, heat and biological degradation [2]. Approximately 10,000 commercially available dyes with over $7 \times 10^{5}$ tonnes of dyestuff are being produced annually across the world today [3]. Synthetic dyes are used widely by various industries such as paper, textile, plastics, paints, food, printing, pharmaceuticals, etc. to colour their products which generate large volumes of coloured wastewater yearly $[4,5]$. The discharge of these coloured effluents in the environment has become a worldwide concern due to the toxic nature of these effluents.

Congo red (CR) is a benzidine-based anionic bisazo dye known to metabolize to benzidine, a known human carcinogen [6]. Congo red (CR) is toxic to animals and plants and thus its introduction to water stream is of potential health, environmental, and ecological concern [7]. Therefore, CR containing effluents have to be efficiently treated before they are discharged into the water bodies or the environment.

Over the past few decades, several processes have been used for the removal of dyes from wastewater such as biological (aerobic and anaerobic), chemical precipitation, coagulation/ flocculation, solvent extraction, membrane filtration, ion exchange, ozonation, electrochemical destruction and adsorption [8,9]. Adsorption process has simplicity of design, more efficient, easy to operate, insensitivity to toxic substances and cost effective, hence, it has been suggested as a potential alternative to the existing physical / chemical /biological methods for the removal of dyes from industrial effluents or waste water [10]. A number of investigations carried out using agricultural materials or the wastes and by product of industries for the removal of dyes from aqueous solutions have been reviewed [11]. However, research interest into production of more economical, easily available and highly efficient adsorbents are still under development. Hence attempts are made in this study to develop a low-cost adsorbent for wastewater treatment using Breadfruit (Artocarpus altilis) seed shell powder.

Breadfruit (Artocarpus altilis) is a member of Moraceae (fig) family. It has been an important staple crop in the pacific and the south eastern part of Nigeria and its peels are left in the environment during processing and consumption. The objective of this study was to investigate the potential of Bread fruit seed shell as an alternative adsorbent for the removal of Congo red dye from aqueous solution. Characterization of BFSS powder was carried out before and after adsorption using FTIR and SEM analysis. The effect of contact time, 
adsorbent dose, initial dye concentration, $\mathrm{pH}$ and temperature were evaluated. Adsorption isotherms, kinetics and thermodynamic parameters were also evaluated and reported.

\section{Experimental}

\subsection{Adsorbent collection and Preparation}

The Bread fruit seed shell powder BFSSP was collected from farm fields in Aboh Mbaise local Government Area of Imo state, Nigeria. This agricultural waste was washed thoroughly with running and distilled water to remove sand, dirt and other impurities present in it and dried in an oven (at $50^{\circ} \mathrm{C}$ ) until all moistures were removed. It was then ground in a mill and sieved in a sieve shaker of particle size $300 \mu \mathrm{m}$. The Breadfruit seed shell powder that passed through the sieve were stored in an air tight container, labelled BFSSP and used as adsorbent without any further pre-treatment.

\subsection{Preparation of adsorbate Solutions}

Analytical grade $\mathrm{CR}$ dye $\left(\mathrm{C}_{32} \mathrm{H}_{22} \mathrm{~N}_{6} \mathrm{O}_{6} \mathrm{~S}_{2} \mathrm{Na}_{2}\right.$; molecular weight $\left.696.68 ; \lambda \max =500 \mathrm{~nm}\right)$ was obtained from the laboratory. A stock solution of CR dye of concentration $1000 \mathrm{mg} / \mathrm{L}$ was prepared by dissolving $1 \mathrm{~g}$ of powder CR dye in 1L of distilled water. Experimental dye solutions of desired concentration were obtained by appropriate dilution of the stock solution.

\subsection{Adsorbent characterization}

Fourier transform infra-red (FTIR) spectrophotometer was used to identify the different functional groups available on the adsorbent sites and their effect on dye adsorption. The FTIR of the adsorbent was taken before adsorption using FTIR spectrophotometer (Shimadzu-8400S). 0.1g of the adsorbent was encapsulated with $1 \mathrm{~g}$ of $\mathrm{KBr}$ spectroscopy grade (merk, Darmstadt, Germany) and by introducing the mix in a piston's cell of a hydraulic pump with compression pressure $15 \mathrm{KPa} / \mathrm{cm}^{2}$, the solid transluscent disk was obtained which was introduced in an oven for $4 \mathrm{hrs}$ at $105^{\circ} \mathrm{C}$ to ensure the non interference of any existing water vapour or $\mathrm{CO}_{2}$ molecules. The FTIR spectrum was then recorded within the wave number range $4000-500 \mathrm{~cm}^{-1}$. In addition, surface morphology and texture of the adsorbent was analyzed using scanning electron microscope (SEM) (Model-PHENOM ProX). Prior to scanning, some quantity of the adsorbent was placed on a double adhesive sticker placed in a sputter machine for $5 \mathrm{sec}$; this gave the adsorbent a conductive property. Sample (adsorbent) stud was fixed on a charge reduction sample holder, and then was charged in the SEM machine.

\subsection{Batch Adsorption Experiments}

Batch adsorption of CR dye onto the adsorbent (BFSSP) was conducted in a 250ml airtight Erlenmeyer flask containing $100 \mathrm{ml}$ of known concentration of the CR dye solution and an accurately weighed amount of the adsorbent. The mixtures in the flasks were agitated on a mechanical shaker operating at a constant speed of 100 $\mathrm{rpm}$. The effect of contact time $(10,20,40,60,80,100 \& 120 \mathrm{~min})$, adsorbent dosage $(0.5,1,2,3 \& 4 \mathrm{~g})$, initial CR dye concentration $(25,50,75,100 \& 125 \mathrm{mg} / \mathrm{L}), \mathrm{pH}(2,4,6,8 \& 10)$ and temperature $(303,313,323,333 \&$ $343 \mathrm{~K}$ ) were evaluated. The flask containing the samples were withdrawn from the shaker at predetermined time intervals, filtered and the final concentrations of CR dye in the supernatant solutions were analyzed using the UV-visible spectrophotometer (Model Hitachi - 2800). The $\mathrm{pH}$ of the solution was adjusted using $1 \mathrm{M} \mathrm{HCl}$ or $\mathrm{NaOH}$. The amount of equilibrium uptake of CR dye was determined using

$\mathrm{q}_{\mathrm{e}}=\frac{\left(\mathrm{C}_{\mathrm{o}}-\mathrm{C}_{\mathrm{e}}\right) \mathrm{V}}{\mathrm{M}}$

$\%$ Dye Removal $=\frac{\left(C_{o}-C_{e}\right) V}{C_{0}} \times 100$

Where $q_{\theta}$ is the amount of dye taken up by the adsorbent at equilibrium $(\mathrm{mg} / \mathrm{g}), C_{\bullet}$ is the initial dye concentration $(\mathrm{mg} / \mathrm{L}), C_{e}$ is the dye concentration at equilibrium $(\mathrm{mg} / \mathrm{L}), M$ is the mass of the adsorbent $(\mathrm{g})$, and $V$ is the volume of the solution, $(L)$.

\section{Adsorption isotherms}

Two adsorption isotherm models were applied to describe the sorption equilibrium in the present study such as Langmuir and Freundlich isotherm models. 


\subsubsection{Langmuir isotherm}

The Langmuir model describes the monolayer adsorption. It assumes a uniform energy of adsorption, a single (homogenous) layer of adsorbed solute at a constant temperature [12, 13].

The linear form of Langmuir equation is given as

$$
\frac{C_{e}}{q_{e}}=\frac{1}{q_{m} K_{l}}+\frac{C_{e}}{q_{m}}
$$

Where $q_{e}(\mathrm{mg} / \mathrm{g})$ is the amount of dye adsorbed at equilibrium, $q_{\mathrm{m}}(\mathrm{mg} / \mathrm{g})$, the amount of dye adsorbed when saturation is attained, $C_{\varrho}$ is the equilibrium dye concentration $(\mathrm{mg} / \mathrm{L})$ and $K_{\mathbb{\Omega}}$ is Langmuir constant related to the binding strength of dye onto the adsorbent.

\subsubsection{Freundlich isotherm}

The Freundlich model is an empirical equation that is very useful in describing the distribution of solute between solid and aqueous phases at a point of saturation. The basic assumption of this model is that there is an exponential variation in site energies of adsorbent and also the fall in heat of adsorption is logarithmic [14].

The linearized form of Freundlich equation is expressed as

$\log \mathrm{q}_{\mathrm{e}}=\log \mathrm{K}_{\mathrm{f}}+\frac{1}{\mathrm{n}} \log \mathrm{C}_{\mathrm{e}}$

Where $K_{f}$ and $n$ are the Freundlich constants that represent adsorption capacity and intensity (strength) of adsorption respectively. The significance of $n$ is as follows: $n=1$ (linear); $n<1$ (chemical process); $n>1$ (physical process) [15].

\subsection{Adsorption kinetics}

The pseudo-first-order and pseudo-second-order kinetic models were applied to study the adsorption kinetics of $\mathrm{CR}$ dye to compute the extent of uptake in the adsorption process.

\subsubsection{Pseudo-first-order kinetic model}

The linear form of the pseudo-first-order kinetic mode is represented by

$\ln \left(\mathbf{q}_{\mathrm{e}}-\mathbf{q}_{\mathrm{t}}\right)=\ln \mathbf{q}_{\mathrm{e}}-\mathbf{k}_{1} \mathbf{t}$

Where $\mathrm{q}_{\mathrm{e}}$ and $\mathrm{q}_{\mathrm{t}}$ are the values of amount of the dye adsorbed per unit mass on the adsorbents at equilibrium and at various time $\mathrm{t}$, respectively, $\mathrm{k}_{1}$ is the Pseudo-first-order adsorption rate constant $\left(\mathrm{min}^{-1}\right)$. The values of $\mathrm{k}_{1}$ and calculated $\mathrm{q}_{\mathrm{e}}$ can be determined from the slope and intercept respectively, of the linear plot of $\ln \left(\mathrm{q}_{\mathrm{e}}-\mathrm{q}_{\mathrm{t}}\right)$ versus $\mathrm{t}$.

\subsubsection{Pseudo-second-order kinetic model}

The pseudo-second-order kinetic model is expressed by

$\frac{t}{q_{t}}=\frac{1}{k_{2} q_{e}^{2}}+\frac{1}{q_{e}} t$

Where $\mathrm{K}_{2}$ is the pseudo-second-order adsorption rate constant $(\mathrm{g} / \mathrm{mg} / \mathrm{min})$ and $\mathrm{q}_{\mathrm{e}}$ is the amount of dye adsorbed $(\mathrm{mg} / \mathrm{g})$ on the adsorbent at equilibrium. The initial adsorption rate, $\mathrm{h}\left(\mathrm{mg} \cdot \mathrm{g}^{-1} \cdot \mathrm{min}^{-1}\right)$ is expressed as:

$\mathrm{h}=k_{2} q_{e}^{2}$

The plot of $\mathrm{t} / \mathrm{q}_{\mathrm{t}}$ versus $\mathrm{t}$ gives a linear relationship which allows computation of $\mathrm{k}_{2}, \mathrm{~h}$ and calculated $\mathrm{q}_{\mathrm{e}}$. 
Among these models, the criterion for their applicability is based on judgment on the respective correlation coefficient $\left(\mathrm{R}^{2}\right)$ and agreement between experimental and calculated value of $\mathrm{q}_{\mathrm{e}}$ [15-17].

\subsection{Thermodynamic parameters}

The thermodynamic parameters such as change in Gibb's free energy change $\left(\Delta \mathrm{G}^{0}\right)$, enthalpy $\left(\Delta \mathrm{H}^{0}\right)$ and entropy $\left(\Delta S^{0}\right)$ were determined using the following equations:

The Gibb's free energy, $\Delta \mathrm{G}$, equation is expressed as follows [18, 19]:

$\Delta \mathbf{G}=-\mathbf{R T}^{\mathbf{T} \ln \mathbf{K}_{\mathrm{ads}}}$

The equilibrium constants (Kads) were calculated according to the following equation:

$\mathbf{K}_{\mathrm{ads}}=\frac{\left(\mathbf{q}_{\mathrm{e}}^{\mathrm{m}}\right)}{\left(\mathbf{C}_{\mathrm{e}}\right)}$

Where: $R$ is gas constant $\left(8.314 \mathrm{Jmol}^{-1} \mathrm{~K}^{-1}\right)$ and $T$ is absolute temperature in Kelvin, qe $\mathrm{e}^{\mathrm{m}}$ is dye concentration on the solid at equilibrium and $\mathrm{Ce}$ is dye concentration in solution at equilibrium.

The Van't Hoff equation is expressed as follows [18- 20]:

$\ln K_{\mathrm{ads}}=\frac{\Delta \mathrm{S}^{0}}{\mathrm{R}}-\frac{\Delta \mathrm{H}^{0}}{\mathrm{RT}}$

Where $R$ is gas constant, $T$ is absolute temperature in Kelvin, $\Delta S^{0}$ and $\Delta H^{0}$ are entropy and enthalpy respectively. The plot of $\ln K_{a d s}$ versus $1 / T$ gives a linear relationship, which allows the computation of $\Delta H$ and $\Delta S$ values from the slope and intercept respectively.

\section{RESULTS AND DISCUSSION}

\subsection{Adsorbent characterization}

The FTIR spectra of BFSSP before and after adsorption (Fig. 1 \& 2) of CR dye were analyzed to determine the vibration frequency changes in their functional groups. For BFSSP before adsorption, various peaks are at $3629.37 \mathrm{~cm}^{-1}\left(\mathrm{O}-\mathrm{H}\right.$ stretch, free hydroxyl from alcohols and phenols), $3421.10 \mathrm{~cm}^{-1}$ (O-H stretch, $\mathrm{H}-$ bonded from alcohols and phenols), $2923.31 \mathrm{~cm}^{-1}$ (C-H stretch, from alkanes), $1733.85 \mathrm{~cm}^{-1}$ (C=O stretch from aldehydes), $1716.63 \mathrm{~cm}^{-1}$ ( $\mathrm{C}=\mathrm{O}$ stretch from ketones), $1697.42 \mathrm{~cm}^{-1}$ (C=O stretch from carboxylic acid), $1647.38 \mathrm{~cm}^{-1}(\mathrm{C}=\mathrm{C}$ stretch$), 1541.49 \mathrm{~cm}^{-1}$ (N-O asymmetrical stretch in nitro compounds) $1457.59 \mathrm{~cm}^{-1}(\mathrm{C}-\mathrm{C}$ stretch in rings), $1244.14 \mathrm{~cm}^{-1}$ (C-N stretch in aliphatic amines), $1155.46 \mathrm{~cm}^{-1}$ (C-H wag in alkyl halides) $1078.74 \& 1029.51 \mathrm{~cm}^{-1}$ (C-O stretch) and $526.76 \mathrm{~cm}^{-1}$ (C-X stretch alkyl halides) [21].

After adsorption of $\mathrm{CR}$ dye it was found out that most of the functional groups on the adsorbent were affected after the dye uptake process. This is judged from shifts in the position of some of the functional groups to lower or higher frequency or band intensity before and after CR adsorption. The functional groups that moved to lower frequency or band intensity after CR adsorption includes: C-H, N-O, C-C (in rings), and C-O from $2923.31 \mathrm{~cm}^{-1}, 1541.49 \mathrm{~cm}^{-1}, 1457.59 \mathrm{~cm}^{-1}$ and $1029.51 \mathrm{~cm}^{-1}$ respectively to $2921.34 \mathrm{~cm}^{-1}, 1541.24 \mathrm{~cm}^{-1}, 1457.35$ $\mathrm{cm}^{-1}$ and $1027.04 \mathrm{~cm}^{-1}$ respectively. The functional groups that moved to higher frequency or band intensity includes: $\mathrm{O}-\mathrm{H}$ (free hydroxyl), $\mathrm{O}-\mathrm{H}$ (H-bonded) and $\mathrm{C}=\mathrm{C}$ from $3629.37 \mathrm{~cm}^{-1}, 3421.10 \mathrm{~cm}^{-1}$ and $1647.38 \mathrm{~cm}^{-1}$ to $3629.40 \mathrm{~cm}^{-1}, 3421.18 \mathrm{~cm}^{-1}$ and $1647.42 \mathrm{~cm}^{-1}$ respectively. This indicates involvement of these groups for CR binding to BFSSP [22].

Furthermore, Fig. 3 shows the SEM image of BFSS powder. It can be observed from Fig. 3 that the external surface of BFSS powder is very irregular with heterogeneous ridges and pores. 


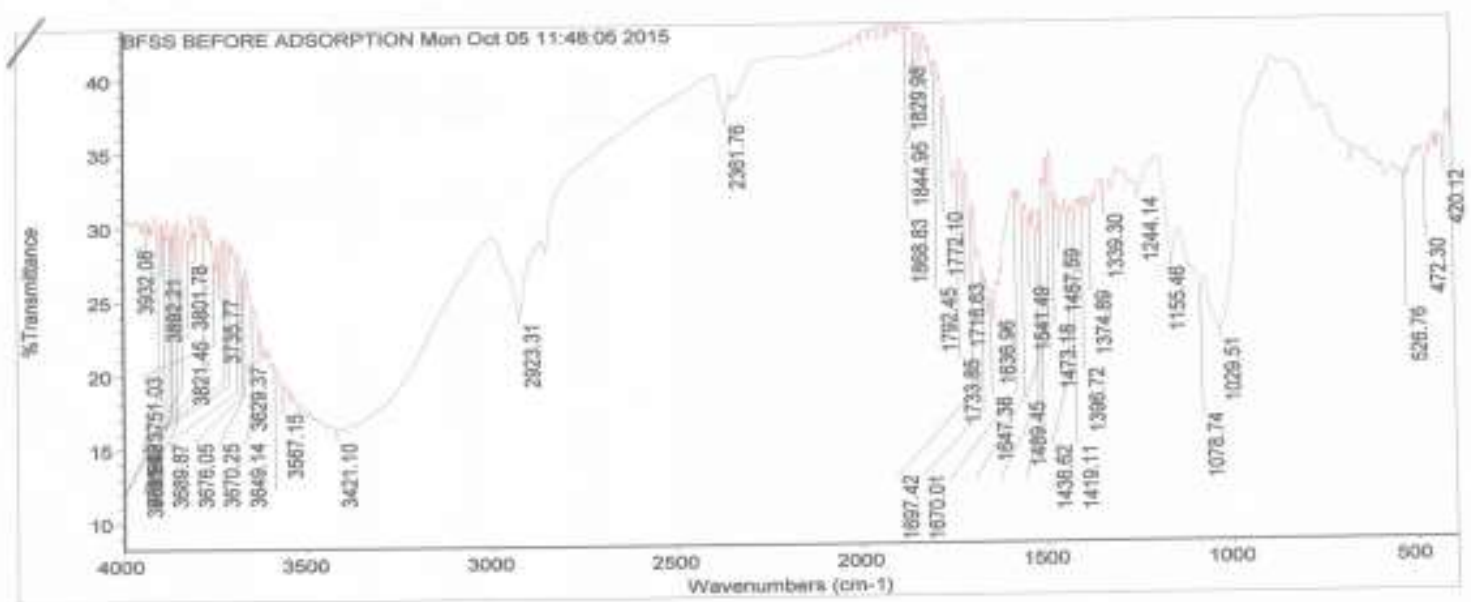

Fig. 1: FTIR Spectra of BFSSP before adsorption

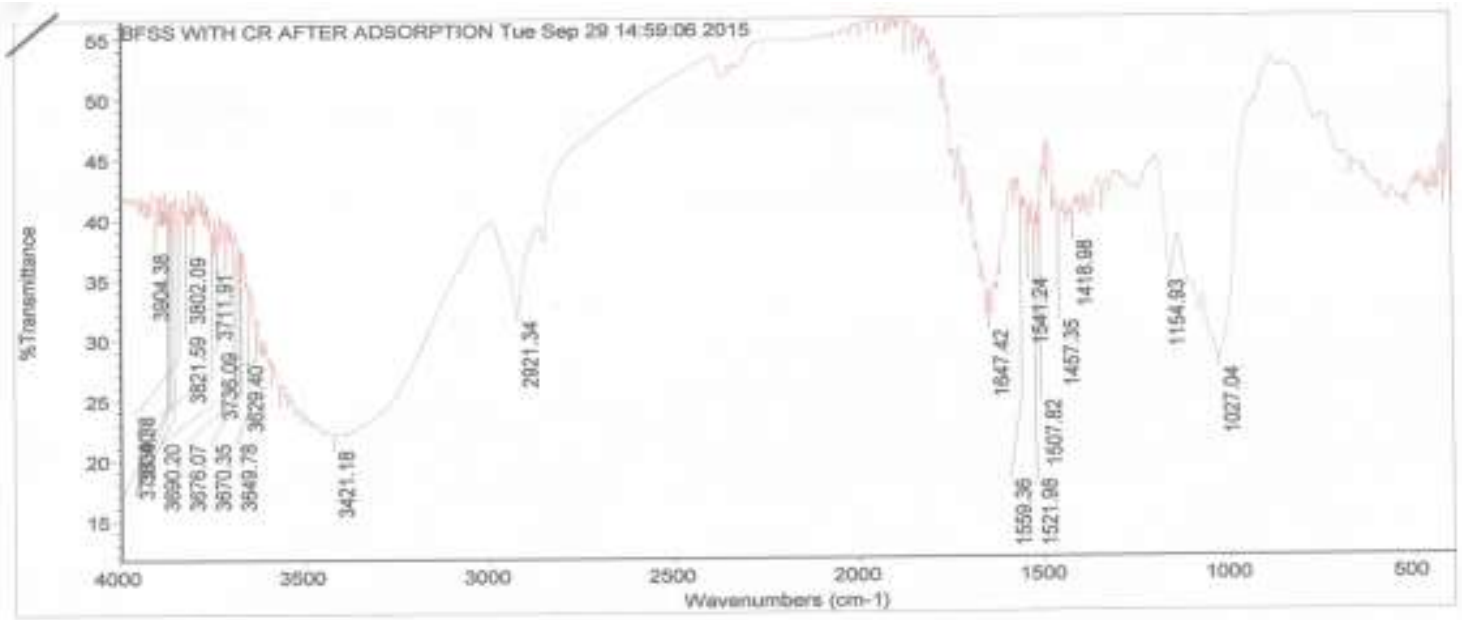

Fig. 2: FTIR Spectra of BFSSP after adsorption

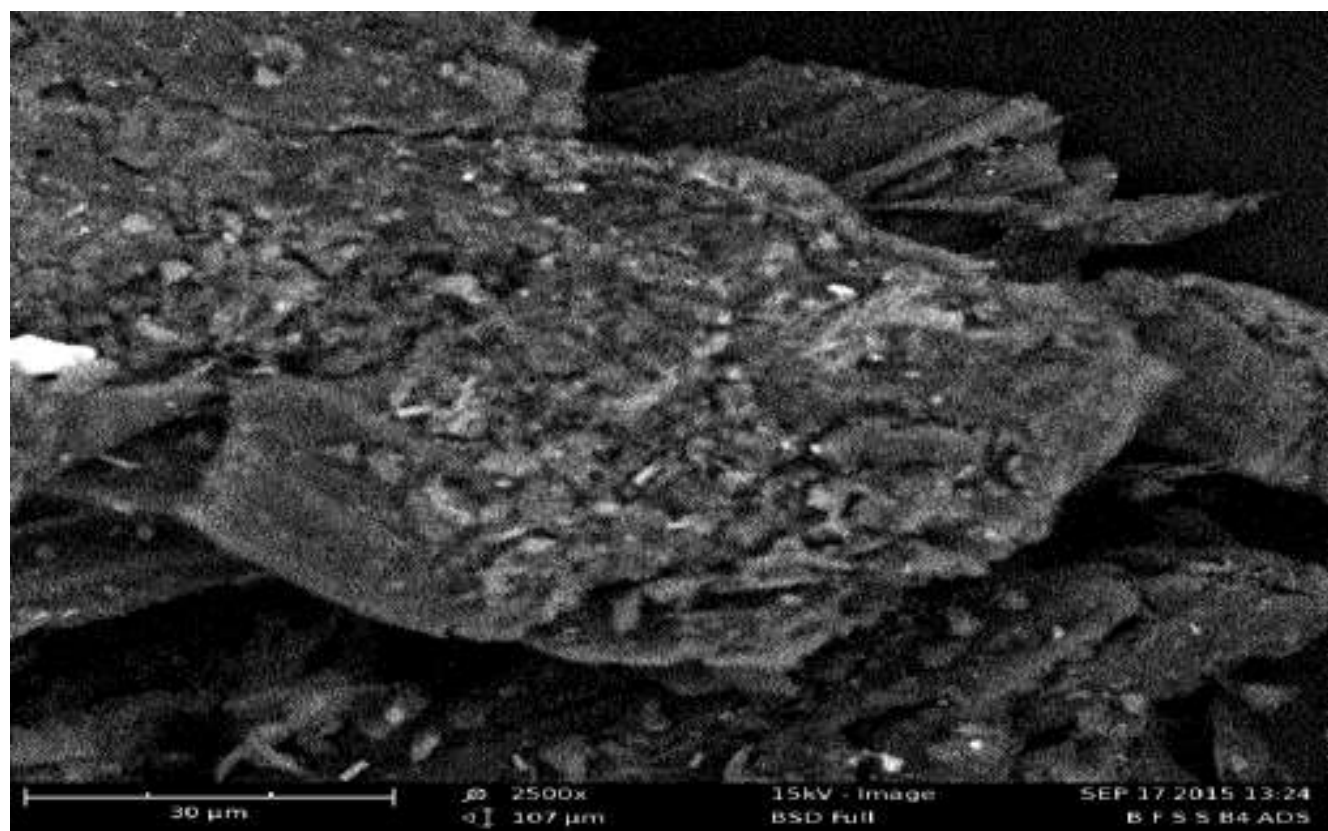

Fig. 3: SEM micrograph of BFSSP surface at magnification 2500x 


\subsection{Effect of Contact Time}

The effect of contact time on the removal of CR dye is depicted in Fig. 4. It can be observed that there was a rapid removal in the first 10 minutes and it proceeds slowly until equilibrium time at 60 minutes. Later it decreases. Similar result has been reported for the adsorption of MB onto raw corn cobs powder [1]. It can be inferred from the rapid sorption rate at the initial stages that there were great quantity of active sites on the external surface of BFSSP which resulted in the swift CR dye removal. The slower rate of removal at the later stages can be accredited to the diffusion of the dyes into the inner part of the adsorbent since the external surface has been occupied by the molecules of the dye [2]. Once equilibrium is attained, there was no further increase since the remaining vacant sites are difficult to occupy probably due to the repulsive forces between the molecules on the adsorbents and the bulk phase $[23,24]$

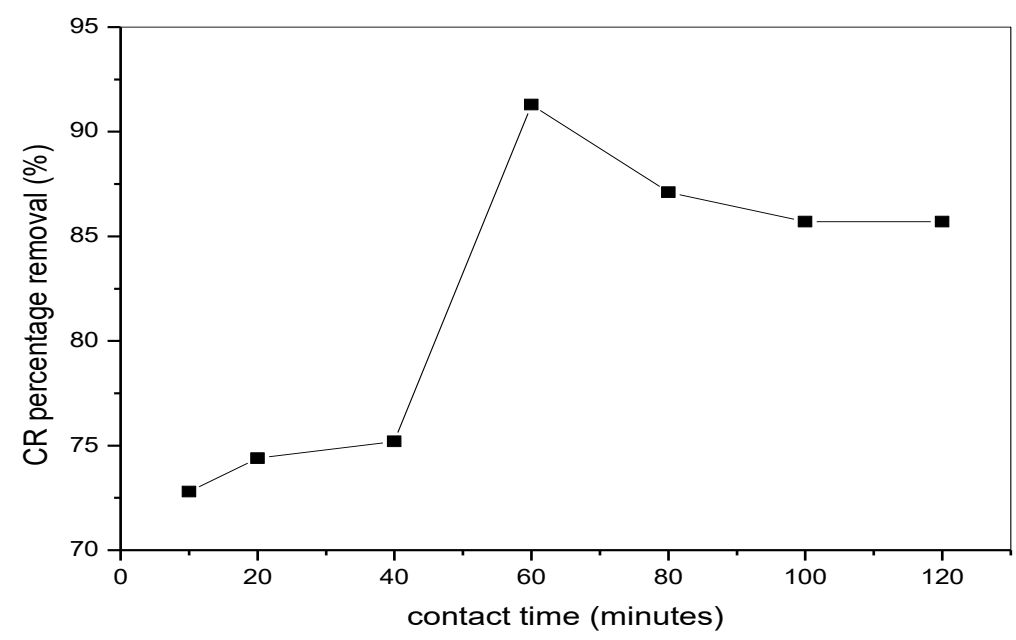

Fig. 4: Effect of contact time on percentage removal of CR dye

\subsection{Effect of Adsorbent Dosage}

The effect of adsorbent dosage on the percentage removal of CR dye is shown in Fig. 5. It can be observed that the percentage removal of CR dye increased with increase in adsorbent dosage. This is as a result of increase in the number of active sites on BFSSP surface with the increase in the adsorbent dosage [25]. Although the percentage removal of CR dye increased with increase of adsorbent dosage, the equilibrium adsorption capacity decreased with increase of adsorbent dosage (figure not shown). This may be due to aggregation of the adsorption sites which limits the availability of all the active sites during adsorption process $[17,26]$.Similar trend has been reported for the adsorption of CR dye by Roots of Eichhornia crassipe [27].

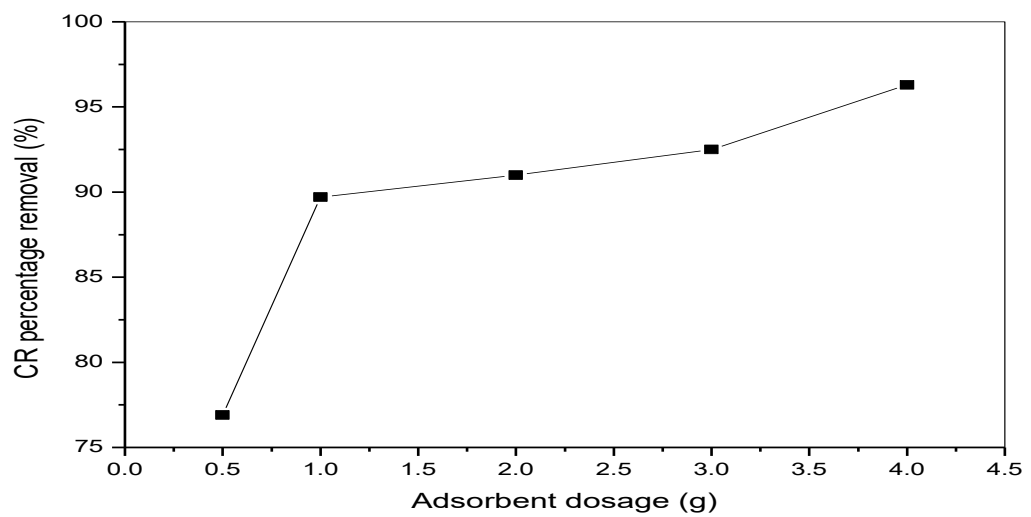

Fig.5: Effect of adsorbent dosage on percentage removal of CR dye 


\subsection{Effect of Initial Dye Concentration}

The effect of initial CR dye concentration is depicted in Fig. 6. It can be observed that the percentage removal of $\mathrm{CR}$ dye increased with increase in initial concentration. This is due to the fact that with increase in dye concentration, more dye molecules are available for adsorption by the adsorbent. This is attributed to the effect of concentration gradient which is the main driving force for the adsorption process (28). Similar trend has been reported by Enenebeaku et al. (1). Moreover, the equilibrium adsorption capacity also increased with increase in initial dye concentration (figure not shown). This is credited to the fact that increasing dye concentration increases the driving force to overcome all mass transfer resistances of the CR between the aqueous and solid phase, leading to an increase in equilibrium adsorption capacity [15, 29].

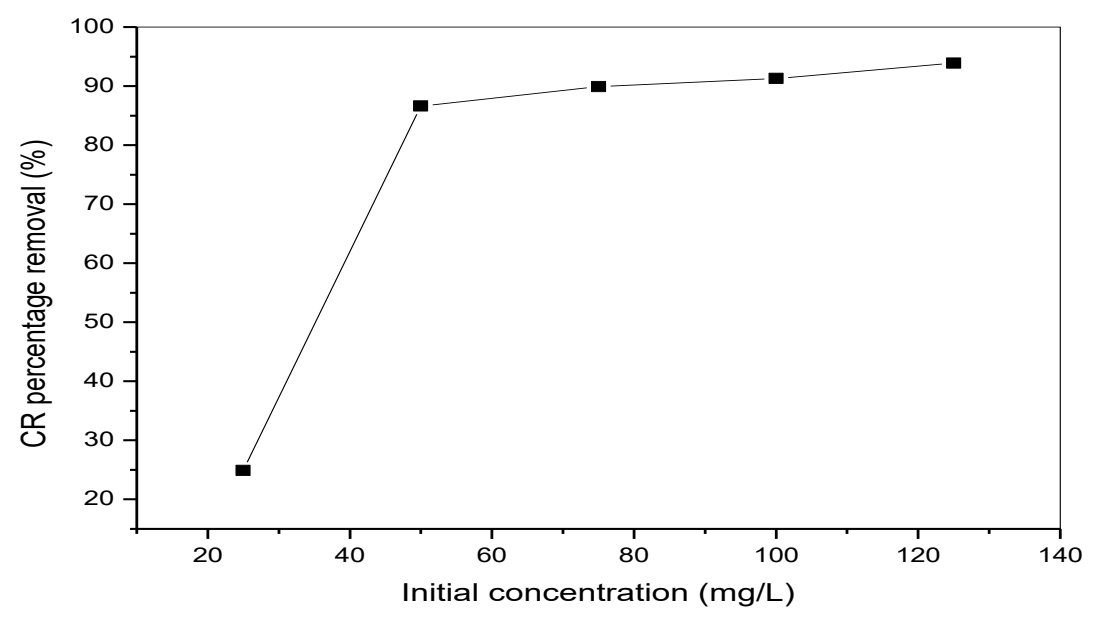

Fig. 6: Effect of initial concentration on percentage removal of CR

\subsection{Effect of $\mathrm{pH}$}

The influence of $\mathrm{pH}$ on the adsorption of CR onto BFSSP is illustrated in Fig. 7. It was observed that the percentage removal and adsorption capacity of CR by BFSSP decreased as pH increased from 2 to 10 . Optimum sorption was obtained at $\mathrm{pH}$ of 2 . The decrease in percentage removal and adsorption capacity with increase in $\mathrm{pH}$ can be attributed to the fact that at high $\mathrm{pH}$ values of the solution, the presence of excess hydroxyl ion in the solution competes with the anionic groups of the CR dye for the adsorption sites on the adsorbent surface. While at low $\mathrm{pH}$ values, the negative charges $\left(\mathrm{OH}^{-}\right)$in the solution decreases and the adsorbent surface is more positively charged, thus enhancing attraction of more amounts of the anions of the CR dye [30].

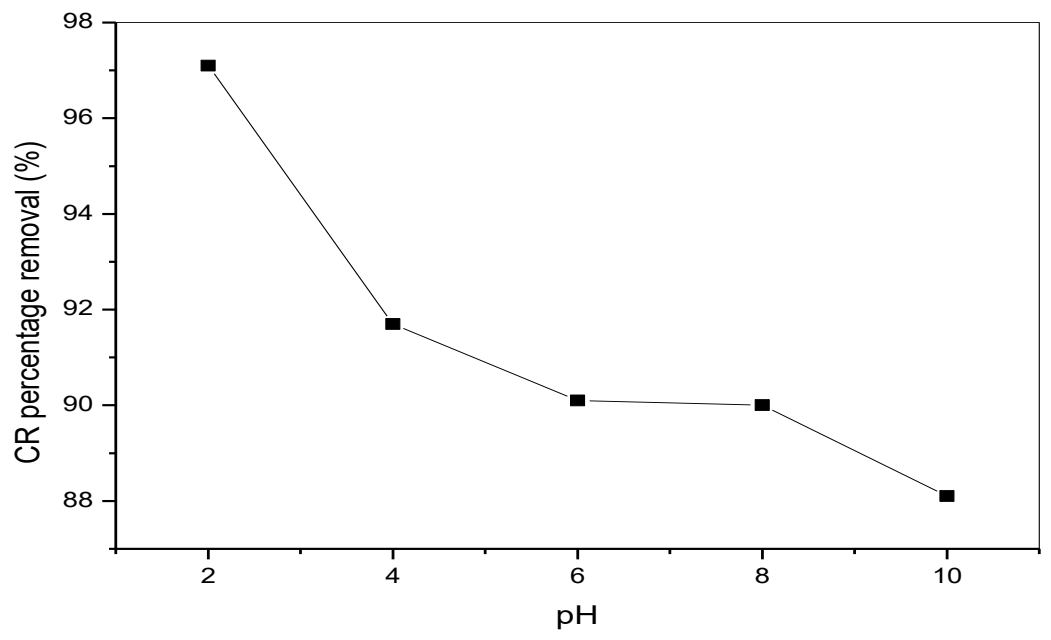

Fig.7: Effect of pH on percentage removal of CR dye 


\section{6. $\quad$ Effect of Temperature}

The influence of temperature on the percentage removal of CR by BFSSP is illustrated in Fig. 8. It can be observed that increase in temperature resulted in decrease in percentage removal of CR by BFSSP. Similar observation has been reported for the adsorption of CR dye onto Ash of Cassia Fistula seeds [31]. This decrease in removal efficiency with increase in temperature can be attributed to the weakening of the physical bonding between the adsorbate (CR dye molecules) and the active sites of the adsorbent (BFSSP). In addition the CR dye solubility also increased with increase in temperature resulting in the interaction between the solute and the solvent to be stronger than that between the solute and the adsorbent. Consequently the solute was more difficult to adsorb $[32,33]$.

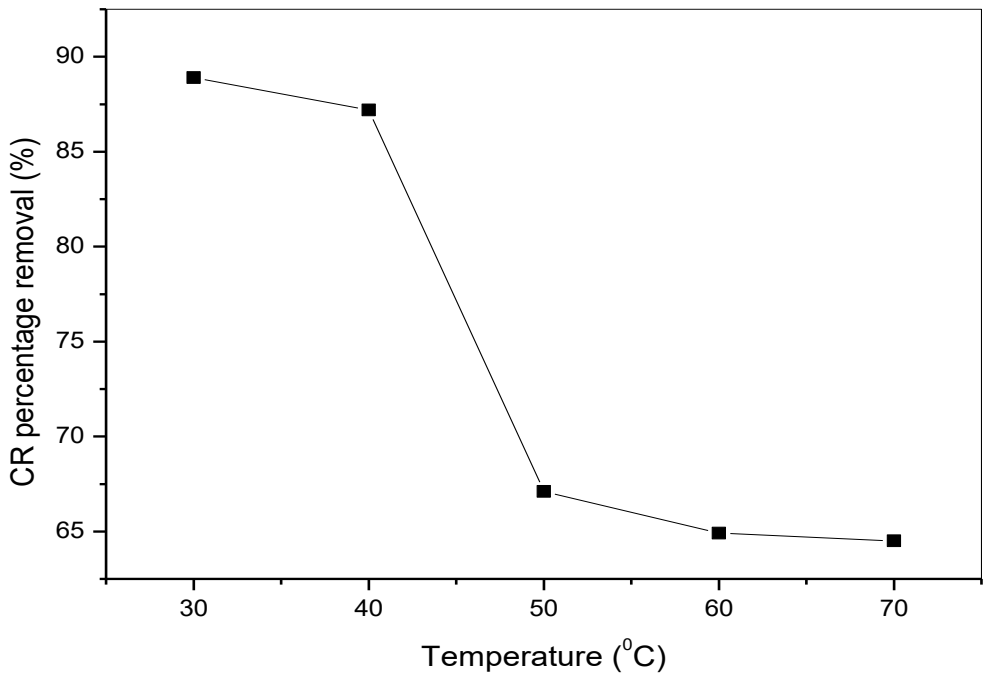

Fig.8: Effect of Temperature on percentage removal of CR dye

\subsection{Adsorption Isotherms}

Langmuir and Freundlich isotherm models were applied to describe the relationship between the CR dye concentration in the bulk solution and that on the BFSS powder's surface. The results are shown in Table 1.

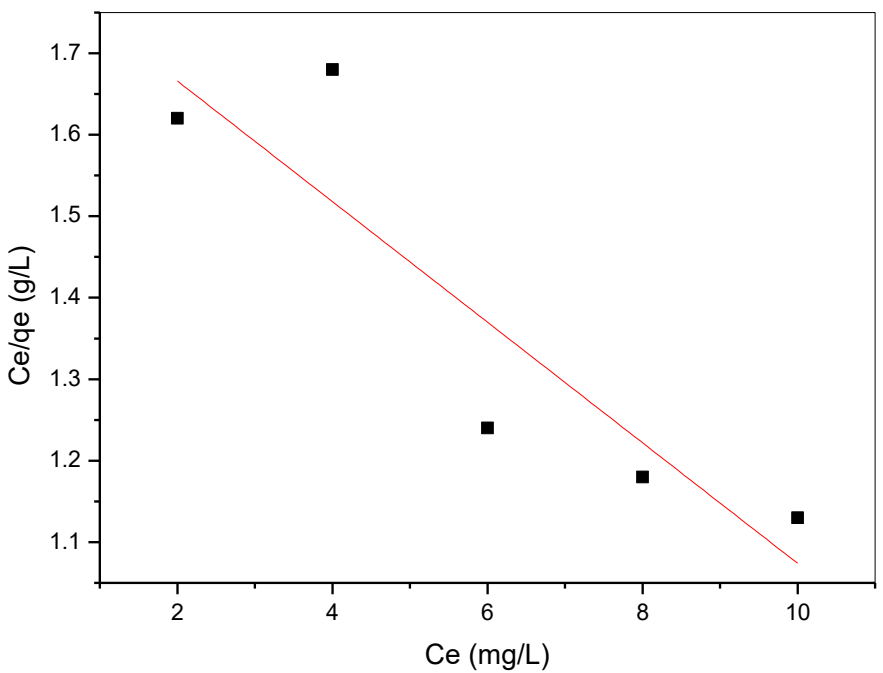

Fig. 9: Langmuir adsorption isotherm plot for CR dye onto BFSSP 


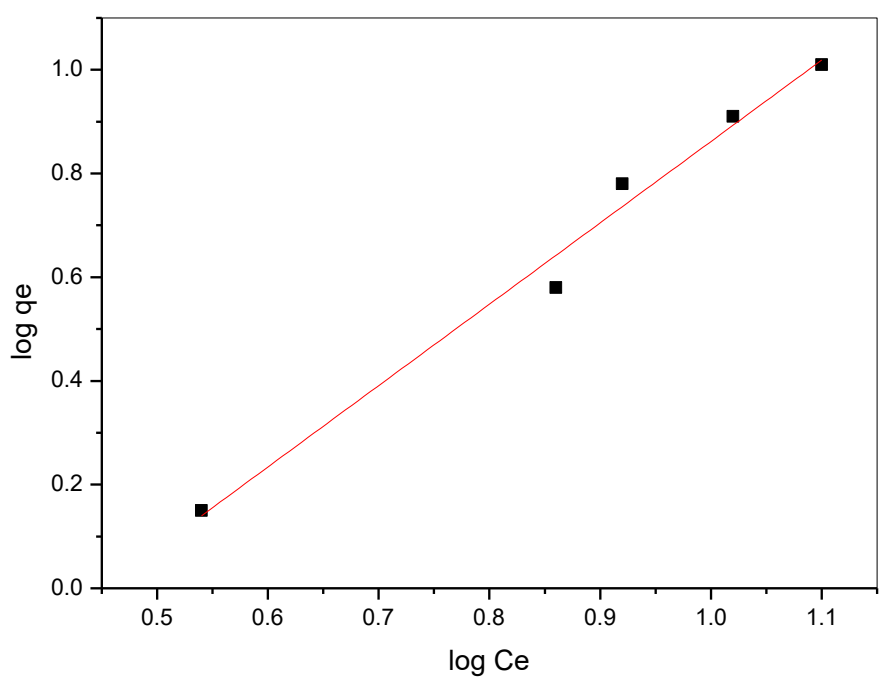

Fig. 10: Freundlich adsorption isotherm plot for CR dye onto BFSSP

Fig. 9 and 10 show the Langmuir and freundlich model plot for the adsorption of CR onto BFSSP respectively. The isotherm parameter and $\mathrm{R}^{2}$ values are summarized in Table 1 . It is evident from the plots and the values of correlation coefficient $\left(\mathrm{R}^{2}\right)$ (Table 1) that the Langmuir isotherms plot was inadequate in describing the adsorption processes. The experimental data fitted well with the Freundlich isotherm model, hence, the Freundlich model is efficient in describing the adsorption of CR onto BFSSP and such adsorptions mainly occurred on the heterogeneous surface of the BFSS powder. In addition, Freundlich isotherm constant, $n$, (Table 1) was found to be less than 1 indicating that the adsorption of CR by BFSSP is a chemical process (15).

Table 1: The Isotherm Parameters and Values of Correlation Coefficient for the Adsorption of CR onto BFSS Powder

\begin{tabular}{rcrc}
\hline Langmuir & $\mathbf{q}_{\mathrm{m}}(\mathrm{mg} / \mathrm{g})$ & $\mathrm{K}_{\mathrm{L}}$ & $\mathbf{R}^{2}$ \\
& 16.00 & 0.04 & 0.600 \\
Freundlich & $\mathrm{K}_{\mathrm{F}(\mathrm{m} / \mathrm{g})(\mathrm{L} / \mathrm{mg})}$ & $\mathrm{n}$ & $\mathbf{R}^{2}$ \\
& 2.527 & 0.694 & 0.958 \\
\hline
\end{tabular}

\section{8. $\quad$ Adsorption Kinetics}

Two kinetic models i.e., pseudo-first-order and pseudo-second-order kinetic models as mentioned earlier were applied to investigate the reaction pathways and potential rate determining steps of the adsorption of CR dye onto Breadfruit seed shell powder.

The pseudo-first-order model did not provide a good fit to the experimental data as the plot of ln (qe-qt) versus $\mathrm{t}$ was non linear with low $\mathrm{R}^{2}$ value (Fig. 11). Moreover, the theoretical and experimental equilibrium adsorption capacity $\mathrm{q}_{\mathrm{e}}$ obtained from the plot varied widely, suggesting the inadequacy of the pseudo-first-order model for describing the adsorption kinetics of CR dye onto BFSS powder The first-order rate constant, $\mathrm{k}_{1}$, the correlation coefficients, $\mathrm{R}^{2}$ and the theoretical and experimental equilibrium adsorption capacity $\mathrm{q}_{\mathrm{e}}$ are given in Table 2.

Furthermore, the kinetic data was best fitted to the pseudo-second-order model. The pseudo-second-order rate constant, $\mathrm{k}_{2}$, the initial adsorption rate, $\mathrm{h}$ and the theoretical and experimental equilibrium adsorption capacity are given in Table 2. The plot of $\mathrm{t} / \mathrm{q}_{\mathrm{t}}$ against $\mathrm{t}$ is depicted in Fig.12. Contrary to the pseudo-first-order model, the fitting of the kinetic data in the pseudo-second-order model showed excellent linearity with high 
correlation coefficients, $\mathrm{R}^{2}$. In addition, there was good agreement between the calculated $\mathrm{q}_{\mathrm{e}}$ and the experimental $\mathrm{q}_{\mathrm{e}}$ values (i.e., the $\mathrm{q}_{\mathrm{e}}$ values were close) indicating that the adsorption of CR dye by Bread fruit seed shell powder followed the pseudo-second-order kinetics. Hence the adsorption process is controlled by chemisorptions [16, 34]. This suggests that the forming of interaction between the adsorbate and the adsorbent on the external surface of BFSSP (film diffusion) is the rate determining step [2].

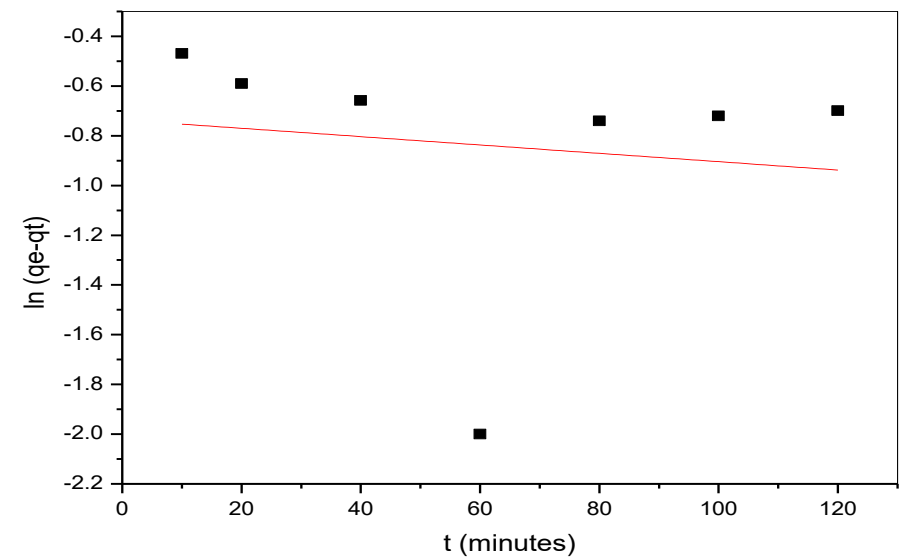

Fig. 11: Pseudo first-order plot for adsorption of CR onto BFSSP.

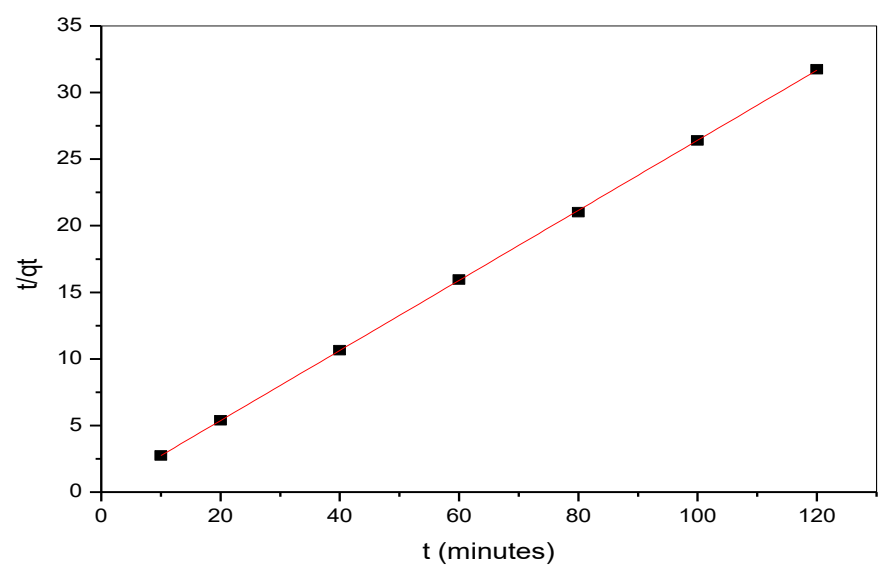

Fig. 12: Pseudo second-order plot for adsorption of CR onto BFSSP

Table 2: Pseudo-first and second order kinetic model parameters for CR adsorption

\begin{tabular}{|c|c|c|c|c|c|c|}
\hline \multicolumn{4}{|c|}{ Pseudo-First Order Model } & \multicolumn{3}{|c|}{ Pseudo-Second Order Model } \\
\hline $\begin{array}{l}\mathrm{q}_{\mathrm{e}} \\
(\exp ) \\
(\mathrm{mg} / \mathrm{g})\end{array}$ & $\begin{array}{l}\mathbf{k}_{1} \\
\left(\mathrm{~g} \cdot \mathrm{mg}^{-}\right. \\
\left.{ }^{1} \mathbf{m i n}^{-1}\right)\end{array}$ & $\begin{array}{l}q_{\mathrm{e}}(\mathrm{cal}) \\
(\mathrm{mg} / \mathrm{g})\end{array}$ & $\mathbf{R}^{2}$ & $\begin{array}{c}\text { h } \\
\left(\mathrm{mg.g}^{-}\right. \\
\left.{ }^{1} \mathrm{~min}^{-1}\right)\end{array}$ & $\begin{array}{l}\mathbf{K}_{2} \\
\left(\mathrm{~g} \cdot \mathrm{mg}^{-}\right. \\
\left.{ }^{1} \mathrm{~min}^{-1}\right)\end{array}$ & $\begin{array}{ll}\mathbf{q}_{\mathrm{e}}(\mathrm{cal}) & \mathbf{R}^{2} \\
(\mathrm{mg} / \mathrm{g}) & \end{array}$ \\
\hline
\end{tabular}

$\begin{array}{llllllll}3.96 & 0.844 & 0.846 & 0.179 & 8.87 & 0.166 & 3.802 & 0.999\end{array}$




\subsection{Adsorption Thermodynamics}

The linear Van't Hoff equation plot for the adsorption of CR onto BFSS powder is shown in Fig. 13. Table 3, presents $\Delta H^{\mathbb{0}}$ and $\Delta S^{\mathbb{0}}$ values obtained from the Van't Hoff plot including the calculated $\Delta G^{0}$ values.

Negative $\Delta G^{\mathbb{0}}$ values obtained at all temperatures (Table 3) indicated the feasibility and the spontaneous nature of CR adsorption onto BFSS powder. It was observed that the values of $\Delta G$ for the adsorption of CR onto BFSS increased with increase in temperature suggesting a rapid and more spontaneous adsorption at the lower temperature. The negative $\Delta H^{\mathbb{Q}}$ value confirmed the exothermic nature of the adsorption process. The negative value of $\Delta S^{0}$ revealed decreased randomness at the solid/solution interfaces [35].

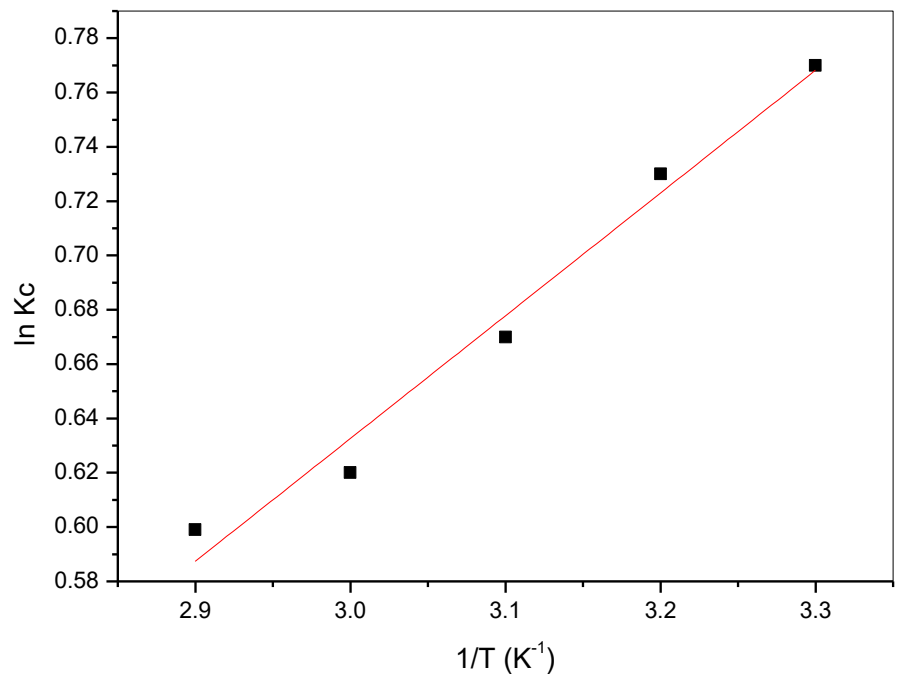

Fig. 13: Van't Hoff plot for the adsorption of CR onto BFSS powder

Table 3: Thermodynamic parameters for the adsorption of CR dye onto BFSSP

\begin{tabular}{llll}
\hline Temperature $(\mathrm{K})$ & $\Delta \mathrm{G}(\mathrm{KJ} / \mathrm{mol})$ & $\Delta \mathrm{H}(\mathrm{KJ} / \mathrm{mol})$ & $\Delta \mathrm{S}(\mathrm{J} / \mathrm{mol} . \mathrm{K})$ \\
\hline 303 & -1940.08 & & \\
313 & -1935.12 & & \\
325 & -1907.05 & -23.30 & -49.99 \\
333 & -1717.23 & & \\
343 & -1708.34 & & \\
\hline
\end{tabular}

\section{CONCLUSION}

The potential of Breadfruit seed shell (BFSS) powder as an effective adsorbent for the removal of CR dye from aqueous medium has been identified. The adsorption of CR onto BFSS powder was found to be influenced by contact time, adsorbent dose, initial CR concentration, temperature and initial $\mathrm{pH}$ of the solution. The optimum adsorption of $\mathrm{CR}$ dye was found at $\mathrm{pH}$ 2. Maximum adsorption capacity was $16.00 \mathrm{mg} / \mathrm{g}$ at $50 \mathrm{mg} / \mathrm{L}$ initial CR concentration. Temperature had strong influence on the adsorption process and the maximum removal was observed at 303K.The equilibrium was attained at $60 \mathrm{~min}$, after which there was no increase in CR adsorption. The kinetic studies revealed that the adsorption process followed the pseudo-second-order kinetic 
model. The study on equilibrium sorption revealed that Freundlich isotherm model gave the best fit to the experimental data. The nature of adsorption of CR onto BFSS powder was chemical adsorption as inferred from Freundlich isotherm model. The calculated thermodynamic parameters indicated a spontaneous and exothermic nature of the adsorption of CR dye onto BFSS powder. The present study showed that BFSS powder can be effectively used as an inexpensive and efficient adsorbent without any modification for the treatment of dye effluents.

\section{REFERENCES}

[1] K.C. Enenebeaku, N.J. Okorocha, and C.O. Akalezi, Adsorptive removal of methylene blue from aqueous solution using agricultural waste: Equilibrium, kinetic and thermodynamic studies, American Journal of Chemistry and Material Science, 2(3), $2015,14-24$.

[2] C. Umpuch, and B. Jutarat, Adsorption of organic dyes from aqueous solution by surfactant modified corn straw, Inter. J. Chem. Eng. Applications, 4(3), 2013, $134-139$.

[3] T. Robinson, G. McMullan, R. Marchant, and P. Nigam, Remediation of dyes in textile effluent: a critical review on current treatment technologies with a propose alternative, J. Biores Tech. 77, 2001, 247-275.

[4] A. Hashem, R.A. Akasha, A.Ghith, and D.A. Hussein, Adsorbent based on agricultural wastes for heavy metal and dye removal: A review, Energy Educ. Sci. Technol. 19, 2007, 69-86.

[5] A. Ezgi, B. Miifit, and Y. Mustapa, Removal efficiency of a calyx [4] arene-based polymer for water-soluble carcinogenic direct azo dyes and aromatic amines, Journal of Hazardous Materials, 162, 2008, 960-966.

[6] R. Ahmad, and R. Kumar, Adsorption studies of hazardous malachite green onto treated ginger waste, Appl. Surf. Sci., 91(4), 2010, 1032-1038.

[7] N. Nasuha, H.Z. Zurainan, H.I. Maarof, N.A. Zubir, and N. Amri, Effect of cationic and anionic dye adsorption from aqueous solution by using chemically modified papaya seed, International Conference on Environment Science and Engineering, 8, 2011, $50-58$.

[8] R. Malik, D.S. Rametke, and S.R. Wate, Adsorption of malachite green on groundnut shell waste based powdered activated carbon, J. Was. Manag. 27, 2006, $1-8$.

[9] G. Crini, (2006) Non-conventional low-cost adsorbents for dye removal: A review, J. Bioreso. Technol. $97,2006,1062-1070$.

[10] S. Chowdhury, and P. Saha, Sea shell powder as new adsorbent to remove basic green4 (malachite green) from aqueous solutions: Equilibrium, kinetic and thermodynamic studies, Chemical Engineering Journal, 164, 2010, 168-177.

[11] C. Allegre, P. Mouline, M. Maisseu, and F. Charbit, Treatment and reuse of reactive dyeing effluents, J. Memb. Science, 269, 2006, 15-17.

[12] K.S. Bharathi, and S.T. Ramesh, Removal of dyes using agricultural waste as low-cost adsorbents: A review. Appl. Water Sci. 3, 2013, $773-790$.

[13] M.A. Al-Ghouti, M.A.M. Khraishch, S.J. Allen, and M.N. Ahmed, The removal of dyes from textile wastewater: a study of physical characteristics and adsorption mechanisms of diatomaceous earth. J. Env. Manag. 69, 2003, 230 - 237.

[14] C. Ng, J.N. Losso, W.E. Marshall, and R.M. Raw, Freundlich adsorption isotherms of agricultural by product based powdered activated carbons in a geosmin-water system, Bioreso. Techno. 85, 2002, 131-133.

[15] P.S. Kumar, M. Palaniyappan, M. Priyadharshini, A.M. Vigensh, A. Thonjiappan, P.A.F. Sebastina, R.A. Tanvir, and R. Srinath, Adsorption of basic dye onto raw and surface-modified agricultural waste, Env. Progress and Sustainable Energy, 33(1), 2013, $87-98$.

[16] N. Sharma and B.K. Nnadi, Utilization of sugarcane baggase, an agricultural waste to remove malachite green dye from aqueous solution, J. Mater. Environ. Sci., 4(6), 2013, 1052-1065.

[17] S. Patil, S. Renukdas, and N. Patel, Removal of methylene blue, a basic dye from aqueous solutions by adsorption using teak tree (Tectona gradnic) bark powder, Inter. J. Env. Sci. 1(5), 2011, 711- 726.

[18] M. Alshabanat, G. Alsenani, and R. Almufarij, Removal of crystal violet dye from aqueous solutions onto date palm fiber by adsorption technique, Journal of Chemistry, 2013, 1-6.

[19] P. Donghee, Y. Yeoung-sang, and M.P. Jong, The past, present and future trends of biosorption, Biotechnology and Bioprocessing Engineering, 15, 2010, 86-102.

[20] A. Ozer, and G. Dursun, Removal of methylene blue from aqueous solution by dehydrate wheat brown carbon, J. Hazard Mater. 146, 2007, 262-269.

[21] M.L. Gary, L.P. Donald, S.K. George, and R.V. James, Infrared spectroscopy, in (4 ${ }^{\text {th }}$ Ed.) Spectroscopy, (Bellingham, Washington: Brooks/Cole) 15-87.

[22] N. Sharma, and B.K. Nnadi, Utilization of sugarcane baggase, an agricultural waste to remove malachite green dye from aqueous solution, J. Mater. Environ. Sci., 4(6), 2013, 1052-1065.

[23] C.H. Wu, Adsorption or reactive dyes onto carbon nanotubes: Equilibrium, kinetics and thermodynamics, J. Hazard, Mater. 144, 2007, 96-98.

[24] C.F Iscen, I. Krian, and S. Iihan, Biosorption of reactive blacks dyes by Fenicillium restrictum: the kinetic study. J. Hazard Mater. 143, 2007, 335-338.

[25] T.F. Hassanein, and B. Koumanova, Evaluation of adsorption potential of the agricultural waste wheat straw on basic yellowish 21, Journal of the University Chemical Technology and Metallurgy, 45(4), 2010, 407-414.

[26] S.T. Akar, A.S. Ozcan, T. Akar, A. Ozcan, and Z. Kaynak, Biosorption of a reactive textile dye from aqueous solutions utilizing an agro-waste, Desalination, 247, 2009, 757-761.

[27] W. C. Wanyonyi, J. M. Onyari and P. M. Shiundu, Adsorption of congo red dye from aqueous solutions using roots of Eichhornia crassipes: Kinetic and equilibrium studies, Energy Procedia, 50, 2014, 862 - 869.

[28] S. Mishra, D.J. Prakash, and G. Ramakrishima, Electronic Journal of Environment, Agricultural and Food Chemistry, 8(6), 2009, $425-436$.

[29] M.H. Baek, C.O. Ijagbemi, O. Se-Jin, and D.S. Kim, Removal of malachite green from aqueous solution using degreased coffee bean, J. Hazard. Mater. 176, 2010, 820-828.

[30] A.L .Prasad, and T. Santhi, Adsorption of hazardous cationic dyes from aqueous solution onto Acacia nilotica leaves as an eco friendly adsorbent, Sustain. Environ. Res., 22(2), 2012, 113-122.

[31] H. Kaur and A. Thakur, Adsorption of congo red dye from aqueous solution onto ash of Cassia fistula seeds: Kinetic and thermodynamic studies, Chem. Sci. Rev. Lett. 3(11S), 2014, 159-169. 
[32] G. Crini, and P.M. Badot, Application of chitosan, a natural aminopolysaccharide for dye removal from aqueous solutions by adsorption processes using batch studies: A review of recent literature, Prog. Polym. Sci. 33, 2008, 399-447.

[33] T.C. Chandra, M.M. Mirna, Y. Sudaryanto, and S. Ismadji, Adsorption of basic dye onto activated carbon prepared from durian shell: Studies of adsorption equilibrium and kinetics, Chemical Engineering Journal, 127(1-3), 2007, 121 - 129.

[34] B.K. Nnadi, A. Goswami, and M.K. Kurkait, Adsorption characteristics of brilliant green dye on kaolin, J. Hazard. Mat. 16(1), $2009,387$.

[35] R. Ahmad, and R. Kumar, Adsorptive removal of congo red dye from aqueous solution using bael shell carbon, Appl. Surf. Sci., $257,2010,1628-1633$. 